\title{
Fetal Stem Cells Use as Antiaging and Rejuvenation Strategies
}

Nataliia Sych $^{1 *}$, Mariya Klunnyk ${ }^{1}$, Iryna Matiyashchuk ${ }^{1}$, Mariya Demchuk ${ }^{1}$, Olena Ivankova ${ }^{1}$, Andriy Sinelnyk ${ }^{1}$, Halyna Kuzmenko ${ }^{1}$, Marina Skalozub ${ }^{2}$ and Khrystyna Sorochynska ${ }^{3}$

${ }^{1}$ Clinical Department, Cell Therapy Center EmCell, Kyiv, Ukraine

${ }^{2}$ Laboratory and Biotechnology Department, Cell Therapy Center EmCell, Kyiv City, Ukraine

${ }^{3}$ Stem Cells Bank, Cell Therapy Center EmCell, Kyiv City, Ukraine

*Corresponding author: Nataliia Sych, Clinical Department, Cell Therapy Center EmCell, Kyiv, Ukraine, E-mail: nataliia_sych@ukr.net

Received date: November 06, 2017; Accepted date: November 30, 2017; Published date: December 02, 2017

Copyright: (c) 2017 Sych N, et al. This is an open-access article distributed under the terms of the Creative Commons Attribution License, which permits unrestricted use, distribution, and reproduction in any medium, provided the original author and source are credited.

\begin{abstract}
Objectives: Our goal was to refine upon the methods of treatment and rejuvenation by way of combination including classical treatment and fetal stem cells (FSCs) administered in suspensions containing fetal liver cells, cells of fetal brain as well as fetal connective tissue.

Materials and methods: 126 persons were involved into our study divided into 2 groups: the patients of the $1^{\text {st }}$ group (67 persons including 40 women of average age $42.35 \pm 0.78$ and 27 men of mean age $44.16 \pm 0.69$ years) were administered FSCs during 3 days. Suspensions of fetal liver were administered $(2$ to $5 \mathrm{~mL}$ per $200.0 \mathrm{~mL}$ saline solution) for $60 \mathrm{~min}$ on treatment day 1 . Treatment day 2 suggested use of suspensions of FSCs extracted from placenta from 4 to $6 \mathrm{~mL}$ s.c. injected to the anterior abdominal wall. Suspensions containing connective tissue cells were administered in the anterior abdominal wall $\left(2.5\right.$ to $4 \mathrm{~mL}$ ). The patients of the $2^{\text {nd }}$ group (59 persons under study, including 28 women of average age $43.21 \pm 0.81$ years and 31 men of mean age by $42.21 \pm 0.72$ years) were additionally performed cosmetology procedures in the region of face and décolleté with application of chorion extract onto provisionally prepared facial skin in volume of $2 \mathrm{~mL}$, followed by plotting with a special thermo-mask on the face.
\end{abstract}

Results: The authors proved effectiveness and safety of treatment by FSCs in persons undergoing therapy for rejuvenation. Significant improvement of hormonal status and levels of electrolytes was recorded under this study. In the $2^{\text {nd }}$ group esthetician noticed significant effects on the skin in the region of face and décolleté over 3 months after FSCs administration.

Conclusion: FSCs use in complex treatment of patients as antiaging and rejuvenation strategies improves hormonal background and skin general appearance in the region of face and décolleté.

Keywords: Fetal stem cells; Antiaging; Testosterone; Thyroid gland hormones

\section{Introduction}

For generations, men have been concerned about attainment and maintenance of youthful vitality, inhibiting a running age clock, along with extending overall lifespan. Nowadays, a great progress in understanding for the aging process exists with respect to frantic effort to delay senescence. At present, factors of risk have been investigated where human might impose effect in order to improve general health, making life quality better as well as increase longevity. Among likely factors we can emphasize: healthy mode of life, appropriate nutrition, normal body weight and freedom from vicious habits [1].

A number of theories have been proposed and all of them could be split into two main categories, in an effort to substantiate the process of aging. The $1^{\text {st }}$ category is comprised of adherence to a concept that aging has programmed nature along with a consolidation that senescence results from accumulation of damage. Quite the opposite, the $2^{\text {nd }}$ category of theories suggests various sources and targets of the damage. It is not necessarily for them to be mutually exclusive in this relevance. Very likely, rates of aging may differ across various species, and programmed senescence can accelerate building up a damage or leads to decreased capacity for repair. What kinds of disruption might happen in a process of aging?

On account of reactive oxygen species (ROS), as primary damaging molecules, not only for mitochondria, but also for the other cell compartments in cell senescence-this theory was proposed by D. Harman in 1956 [2] and has remained entrenched up to this day. A decline in ROS production by use of mitochondria-targeted rechargeable antioxidants contributed to the background for the approach established by V.P Skulachev for prevention of age-related diseases [3]. It is challenging, that a role of ROS in age-associated pathologies has undergone several revisions for the recent years. Originally, damaged mitochondria were believed to be able to promote enhanced ROS generation and thus accelerate aging [4]. However, it was confirmed that most mitochondrial deficiencies do not end up with an elevated ROS, but with fully inactivated mitochondria, which supported a hypothesis that cells lacking a mitochondrial function can bear a threat for the whole organism [5].

A process of aging is associated not only with a formation of metabolic by-products, but also with the dysregulation of regulatory pathways. For instance, aging violates the balance between pro-and 
anti-inflammatory components, which promote a chronic inflammation. The causality between such inflammatory processes and age-related disorders was highlighted in the inflamm-aging theory of Franceschi [6]. Increased predisposition to inflammatory diseases in early age of patients, owing to protective barrier against infection, had been proved to be detrimental in the elderly. In addition, because of imbalance with pro-and anti-inflammatory responsiveness, aging can also impair the other important pathways. V.M. Dilman, a scientist from Russia, to substantiate aging made a concept by neuroendocrine theory (hypothesis of elevation) [7]. This theory emphasizes presence of self-regulatory mechanisms to maintain homeostasis-negative feedback pathways. Hypothalamus-pituitary-adrenal axis belongs to one of the fundamental systems. An elevation of the threshold of hypothalamus to negative feedback signaling accounts for the unfavorable age-related changes in human health; specifically, declined reproductive function [8]. Development and experimental verification of the elevation hypothesis proved this accomplishment to be essential in aging research.

Sexual hormones are especially important for reproductive functions, and later in life for metabolism, cardiovascular system, as well as overall well-being of the women. Menopause, which is characterized by a dramatic decrease in estrogen secretion, being accompanied by diminishing levels of progesterone and androgen, triggers a multiple loss of functions [9-13]. Particularly in the regions of the brain (central, vegetative nervous system, cognition, memory, psyche, and libido), the bones, the skin, connective tissue, peripheral vessels, and cardiovascular system. Ultimately, this causes adjustment in those systems; such a restructuring can lead to increased oxidation and a weakened lipid metabolism, resulting in high cholesterol levels and enhancing the risks of Alzheimer's disease, myocardial infarction, and apoplexy.

Skin fading is a part of the natural human "aging mosaic" that becomes evident and follows some different pathways in various organs, tissues and cells with time. In contrast, all aging signs in internal organs are concealed from the surrounding "eyes", whereas skin accounts for the primary apparent traces of the time passing.

Classical therapy for treatment of the patients to improve skin condition and human organism in general also exists. This approach suggests use of non-invasive methods which consist in use and applications of masks containing components of hyaluronic acid, collagen, elastin, algine and various types of massages. We can emphasize also injecting methods to influence the skin that are presented as mesotherapy (application of different synthetic substances-vitamins, microelements, peptides, polypeptides etc.), biorevitalization and bio-regenerative processes. Substantial disadvantage of likely methods use is a probability of allergy reactions to such synthetic components as well as skin traumatization related to injecting methods and techniques. Simultaneously, chorion preparation containing natural biologically active supplements is regarded as safe and cannot cause allergy response. Biologically active substances can easily pass through the skin and create the most optimal conditions for proper cells regeneration in the organism [14-16].

The purpose of cosmetology treatment is increasing efficacy of systemic FSCs therapy as well as improvement of facial skin condition without disruption of its sustainability, however, with maximal productive value of such effects.
The principle of action (that is, a theory which explains efficacy of embryonal extracts of chorion) is substantiated by rather simple logical pattern: in a period of embryo-fetal development, fetal cells are actively divided (prone to proliferation) owing to numerous growth factors of cells which exist. Considering that cells are generated before long, scientists encouraged an idea of tissue extracts application for skin renewal. Chorion extract has been known to contain a large amount of active elements and cells: growth factors (GF) representing a group of protein structures similar to hormones. These factors maintain a broad spectrum of biological influence on various cells in the organism and are prone to regulate blood supply to the tissues as well as nutrition for the cells. Such substances are produced by non-specialized cells of all tissues and affect both adjacent and distant target cells owing to their transport with blood. To such factors of growth one can refer epidermal and insulin like growth factors, platelet-derived growth factor (PDGF), vascular endothelial growth factor (VEGF), basic fibroblast growth factor (bFGF) and many others.

Both biological processes of human aging and various factors of risk can affect senescence of the organism; these two constituents are interrelated. Stem cell treatment is believed to be one of the best methods of treatment in patients with problems of aging. Such treatment can strengthen the organism in general, contribute to internal organs functioning and improve life quality of the patient; it can also reinforce human organism with a new building material and promote positive influence on microenvironment of proper stem cells of the patient [17].

FSCs are known to preserve their capacity to growth, multiplication, differentiation, migration and interconnection with the other cells. If compared to cells of mature tissues they reveal better proliferation property. Their administration is also effective owing to formation of a great number of growth factors. Cells of fetal liver can produce a significant value of growth factors, neurotrophic factor, cytokines, and interleukins contributing to cells survival and growth, proliferation and cellular differentiation. FSCs can preserve capacity to stimulating regeneration due to the host cells which surround them.

Transplantation of FSCs has advantages if compared to stem cells use from tissues of adult donor, as it does not cause rejection of transplanted tissue. Substitution of damaged specialized stem cells in the organs of recipients is important for effectiveness of therapy. Immaturity of fetal immune system in early stages is also not less significant aspect of immunology. Suspensions including cells of hematopoietic tissue in early embryonic period are not containing mature lymphocytes; therefore, they are not able to recognize and do not subject tissues in a "foreign" recipient to an attack; graft-versushost disease is not the case. FSCs are tolerant to hypoxia because of glycolysis; therefore, ischemic lesions at time of manipulations in vitro do not influence cells viability. Proliferative or immature FSCs monumentally do not have long processes or strong cell-to-cell adhesion and, therefore, they are less prone to destruction at time of producing suspensions with inclusion of the isolated cells. Such a property helps preserving viability of these cells that is higher compared with adult stem cells, following the process of cryopreservation and application of FSCs in suspensions for injection [18].

In view of the above, a true task of antiaging and regenerative medicine is complex. It suggests optimal maintenance of «intrinsic physiology processes» along with esthetic improvement of general appearance in human; preserving internal body health altogether with improvement and recovery of all physiological processes in human 
organism. Restoration of the levels of vitally important biochemical substances; prevention of inflammatory processes; detoxication and evacuation of wastes; recovery of normal hormonal balance and slowing down premature fading of the cells are rather significant concerns for better human general appearance.

Researchers Demchuk MP, et al. managed to prove safety and effectiveness of fetal stem cells use for anti-aging and rejuvenation [17].

Aim of study: Our main objective in this study was investigating FSCs effects on essential processes of aging in human body.

\section{Material and Methods}

Our study included 126 individuals who were divided into 2 groups: 67 persons were allocated into the $1^{\text {st }}$ group (including 40 women, with average age $42.35 \pm 0.78$ years; and 27 men, with average age $44.16 \pm$ 0.69 years) who were administered fetal stem cell (FSC) suspensions during 3 days of treatment. For the $1^{\text {st }}$ day we conducted intravenous infusion of suspension containing fetal liver in a dose ranging from 2 to $5 \mathrm{~mL}$, per $200 \mathrm{~mL}$ of physiological solution within a period of 60 minutes. For the $2^{\text {nd }}$ day suspension was prepared using FSCs extracted from placenta in a dose ranging from 4 to $6 \mathrm{~mL}$ and injected to the anterior abdominal wall; whereas during treatment day 3 the patients were administered a suspension including connective tissue for subcutaneous injecting to the region of anterior abdominal wall in dosage ranging from 2.5 to $4 \mathrm{~mL}$.

The patients of the $2^{\text {nd }}$ group (composed of 59 persons including 28 women with average age of $43.21 \pm 0.81$ years, and 31-men, with average age of $42.21 \pm 0.72$ years) were additionally performed cosmetology procedures in the region of face and décolleté with topical application of chorion extract onto provisionally prepared facial skin in a volume of $2 \mathrm{~mL}$, followed by plotting with a special thermo-mask on the face. This procedure envisages use of natural routes for embedding of preparation. Nowadays, scientists emphasize 3 known ways for diffusion of substances into the skin: trans-follicular (via hair follicles), trans-glandular (via excretory ducts of sweat gland coil) and transepidermal (via non-affected stratum corneum). The principal mode of substances distribution to the skin is believed to be by virtue of epidermal layers.

Patients of both groups were made blood withdrawal for hormones (Anti-Mullerian Hormone (AMH), defined by immunoassay method using analyzer Beckman Coulter, USA, (2014); testosterone and its fractions; hormones of thyroid gland, determined by means of immunochemical electrochemiluminescence assessment (ECLIA) method using apparatus Cobas 6000, Roche Diagnostics, Switzerland (2015) and blood electrolytes-those were studied using potentiometric method by the apparatus Cobas 6000, Roche Diagnostics, Switzerland (2015) prior to treatment, over 3 and 9 months after FSCs therapy. All patients were examined by a doctor-aesthetician. The patients of both groups before cosmetology procedure underwent visual inspection of skin for presence of rhytids including study of depth of such wrinkles; existing pigmentation and skin tightness, its moisture barrier (both on visual inspection and by means of special device (Dermochek, Italy, 2016).

Patients in both groups were compared according to their age, risk factors and way of life (those were not kept on a special diet were not administered treatment using antidepressants). Criteria for noninclusion for the patients into the study were the next: persons not suffering from any oncology or cardiovascular diseases; individuals with age younger than 18 years and older than 75 ; studied patients were not takers of psychoactive substances.

Special formulae were applied for the patients to calculate biology age: for women: RBAw (reference biological age) $=1.463+0.415 \times$ APP (arterial pulse pressure) $+0.248 \times \mathrm{BM}$ (body mass) $+0.694 \times \mathrm{SHA}$ (subjective health assessment)-0.14 $\times$ SMB (static mass balancing). In men calculation was as follows: RBAm (reference biological age $=26.985+0.215 \times$ SBP (systolic blood pressure) $-0.149 \times$ IBH (inhale breath-holding) $+0.723 \times$ SHA (subjective health assessment)-0.151 $\times$ SMB (static mass balancing). We assessed actual biological age (ABA) with calculation in accordance with the following formulae: Women: $\mathrm{ABAw}=0.581 \times \mathrm{CA}$ (chronological age in years) +17.24 Men: $\mathrm{ABAm}=0.629 \times \mathrm{CA}$ (chronological age in years) +18.56 Rate of aging=RBA-ABA. If $\mathrm{RBA}-\mathrm{ABA}=0$-which corresponds to statistical normal ranges. If $\mathrm{RBA}-\mathrm{ABA}>0$, then a rate of aging is elevated; in case RBA-ABA 0.95-corresponds to accelerated rate of aging. Taking into consideration the aging rate index (ARI), biological age in men $(B A m)=A R I m \times(C A-21)+21$ biological age in women $(\mathrm{BAw})=\mathrm{ARIw} \times(\mathrm{CA}-18)+18$.

The patients of the main group underwent a separate course of treatment using FSCs suspensions. Before FSCs transplantation, all patients were informed about the plan of treatment and the other procedures for diagnosis-making; later the patients reported about their health state and were informed regarding the results of laboratory and instrumental studies. All participants were acquainted with all descriptions of FSCs suspensions and the corresponding modes for fetal stem cells transplantation. When doctors presented the clarified treatment program, all patients in the group under study signed their written informed consent for therapy using FSCs.

\section{Procedure of stem cells administration}

In laboratory premises our collaborators produced 3 preparations including suspensions of cryopreserved stem cells: one of them contained cells of human fetal liver; the second-stem cells of fetal brain and the third-with inclusion of suspended stem cells of human connective tissue. For this purpose, in conditions of operative room and, following all rules of aseptics and antiseptics, fetal material was received-more specifically: tissues of fetal liver, fetal brain and connective tissue extracted from human fetus 6 to 10 weeks of gestation, died resulting from medical abortion in clinical cases when pregnancy was interrupted owing to social indications at absence of developmental pathology or infection of fetus and with an evidence of informed consent previously obtained from the woman. For the purpose of safety, both women-donors, as well as readily-made fetal stem cells were tested for parasites, viral, mycotic and bacterial infections such as syphilis (Treponema pallidum), toxoplasmosis (Toxoplasma gondii), Mycoplasma genitalium, Ureaplasma urealyticum, Ureaplasma parvum, and Chlamydia trachomatis, human immunodeficiency virus 1 and 2, hepatitis $B$ virus, hepatitis $C$ virus, rubella and Epstein-Barr virus, cytomegalovirus, herpes simplex virus 1 and 2 .

Extracted fetal tissues are then placed into sterile transport medium with Hank's Buffered Salt Solution (HBSS). In sterile conditions such tissues are separated and homogenized using HBSS. Then all suspensions received are exposed to fine filtration for further cryopreservation. Dimethylsulphoxide (DMSO) is used as a freezing protectant for storage of the suspensions. After that duly prepared suspensions with FSCs are bottled into the cryovials in volume of 0.1$1.0 \mathrm{~mL}$. Cryopreservation of FSCs is made using programmed deep- 
freeze cabinet according to a specially adjusted program. Suspensions containing stem cells obtained from fetal liver, cells of fetal brain and connective tissue of human fetus are preserved inside of a cryobank with liquid nitrogen at minimal elicited temperature by $-196^{\circ} \mathrm{C}$. Directly before administration, vials with suspensions are taken off liquid nitrogen for thawing in a water bath at temperature $+37^{\circ} \mathrm{C}$ and being soaked until liquid phase is attained. Subsequent manipulations are prosecuted at room temperature with strict adherence to the aseptic rules. A period of transit for the defrosted suspension containing fetal cells of liver and fetal brain shall not exceed 10 minutes.

The study was approved by the local ethical committee and enrolled to the public register at the Ministry of Education and Science of Ukraine; approval was promoted by the local ethical board at the City Clinical Hospital for Accident and Emergency.

\section{Statistical assessment}

Average values and their standard deviations were calculated, as well as significant differences had been determined using Statistica 12.0. Student's T criteria were used in the data analysis. Differences were regarded as statistically significant if $\mathrm{p}<0.05$.

\section{Results}

During the $1^{\text {st }}$ month the patients experienced a syndrome of early post-infusion improvements and were presented with higher physical and emotional activity, improved sleep, better mood and appetite. Following FSCs administration including cryopreserved cells of fetal liver we did not observe any complications or adverse reactions; the same as no evidence of graft-versus-host disease (GVHD) after treatment. Based on cosmetologist's observations, as well as according to subjective feelings of the patients in both groups during the $1^{\text {st }}$ month after FSCs therapy, we recorded primary improvement of skin, specifically its moisture barrier and better skin tightness. Among the patients of the $2^{\text {nd }}$ group, moderate lifting of facial skin as well as less depth of rhythids were additionally observed. Likely growing effects were emphasized by the patients of the $2^{\text {nd }}$ group over 3 and 9 months after FSCs therapy. In addition, patients with hyperpigmentation noticed some pigmented spots lightening on their facial skin. Patients of the $1^{\text {st }}$ group reported about preserved skin effects during 1.5-2 months following application of FSCs.

Special diagnostic algorithm was established for examination of persons undergoing a course of antiaging and rejuvenation therapy.

The 1st step: compilation of «aging estimate», that is a collection of general anamnesis. Within a process of history taking, one has to identify hereditary predisposition to various diseases, ecology surroundings and housing conditions, evidences of unhealthy habits, tempo of living, resistance to stress and emotional type of individual. Faced with a specialist in regenerative medicine one can envisage the main task to ascertain the patient is intended to strict following all recommendations of the doctors along with fulfillment of all efforts.

The next step suggests general examination of the patient. Its main task is to estimate the level of physical development, psycho-emotional tolerance in the patient, evidences of obesity, swellings, defining associated diseases, «diseases in elderly aged» in particular; as well as functional disturbances of organs and systems in human. One shall account for such factors like family type of nutrition, mode of life etc. By study of acquired risks, doctor must consider circumstances of the patient's life (housing ecology, characteristics of working place), episodes with exposure to radiation, intoxications, smoking, alcohol abuse and injecting drugs use; psychic atmosphere at home and at the working place; possibility of development of chronic fatigue syndrome and the other factors.

Risk factors in the patients under study were distributed in the figures 1 and 2 .

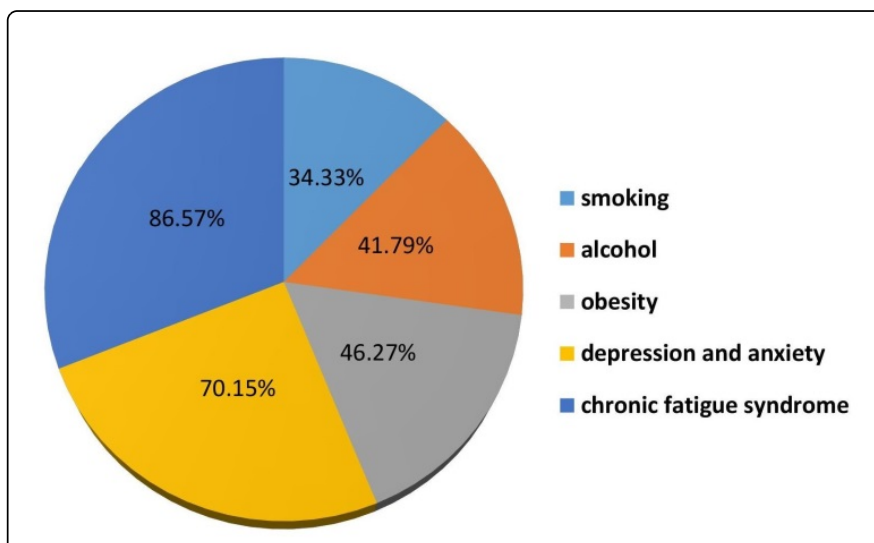

Figure 1: Pattern of Risk factors among the patients of the $1^{\text {st }}$ group.

As it has been known, menopause in women is regarded as common age-related response in the human organism that predisposes to osteoporosis and a range of the other disturbances. In addition, with age women experience a decrease in reproductive functions of ovaries and likely estimation could be identified based on the results of AntiMullerian Hormone tests (Figure 3).

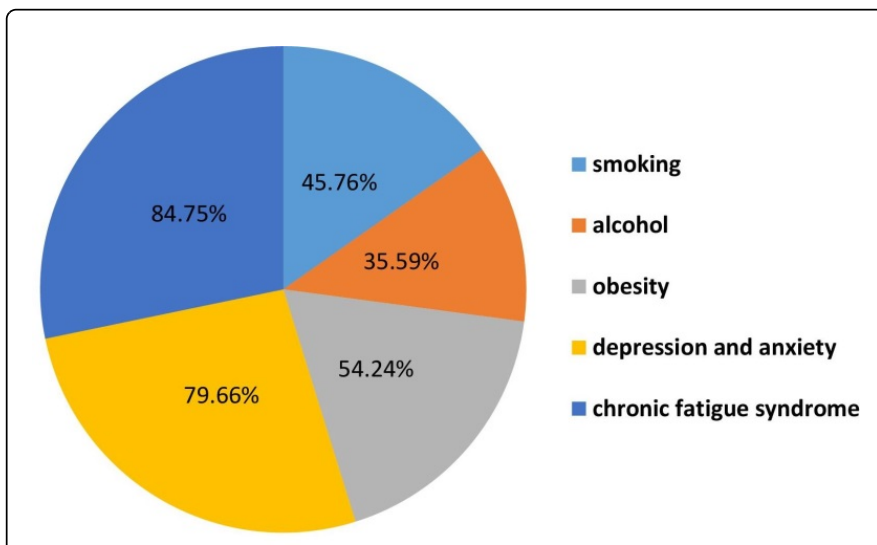

Figure 2: Pattern of Risk factors among the patients of the $2^{\text {nd }}$ group.

The ranges of AMH were below normal limits among the patients of both groups $\left(0.23 \mathrm{ng} / \mathrm{mL}\right.$ in women of the $1^{\text {st }}$ group and $0.27 \mathrm{ng} / \mathrm{mL}$ in the $2^{\text {nd }}$ group). Over 3 months following FSCs therapy in patients of the $2^{\text {nd }}$ group-the levels of AMH were at lower limit of normal $(1.2 \mathrm{ng} /$ $\mathrm{mL}$ ), whereas among the patients of the $1^{\text {st }}$ group AMH was below normal limits $(0.9 \mathrm{ng} / \mathrm{mL})$. Over 9 months after treatment significantly increased level of AMH was recorded among the patients of both groups ( 4.5 and $6.7 \mathrm{ng} / \mathrm{mL}$ ), respectively. 


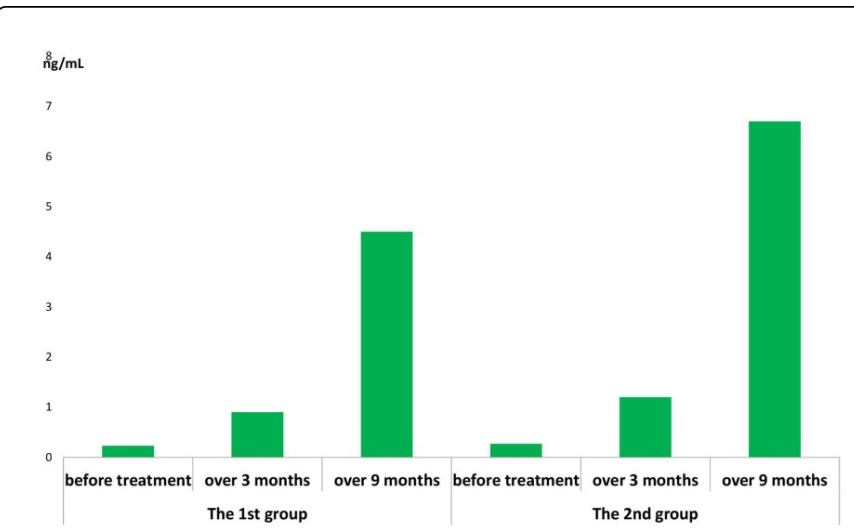

Figure 3: Anti-Muller hormone ranges among the women of both groups in a process of treatment.

Climax in men could be evaluated after the age of 40-when they reveal physiological reduction of circulating testosterone in blood with compensatory onset of abnormality in hypothalamic regulation, associated with growth in the levels of luteinizing and follicle stimulating hormones (FSH) and, simultaneously, a decrease in somatotrophic hormone and insulin like growth factor (Figure 2). Special attention should be concentrated upon the ranges of testosterone. This hormone is known to stipulate masculine signs among the individuals. Assessment for the ranges of testosterone must be conducted in men to reveal problems with sexual maturation and sexual dysfunction. The level of testosterone is defined for assessment of erectile dysfunction, infertility, and gynecomastia; in diagnosis of osteoporosis and after prescription of hormonal replacement therapy. Evaluation of dynamics of testosterone ranges and its functions in men of both groups under study was performed as described in the figure 4 .

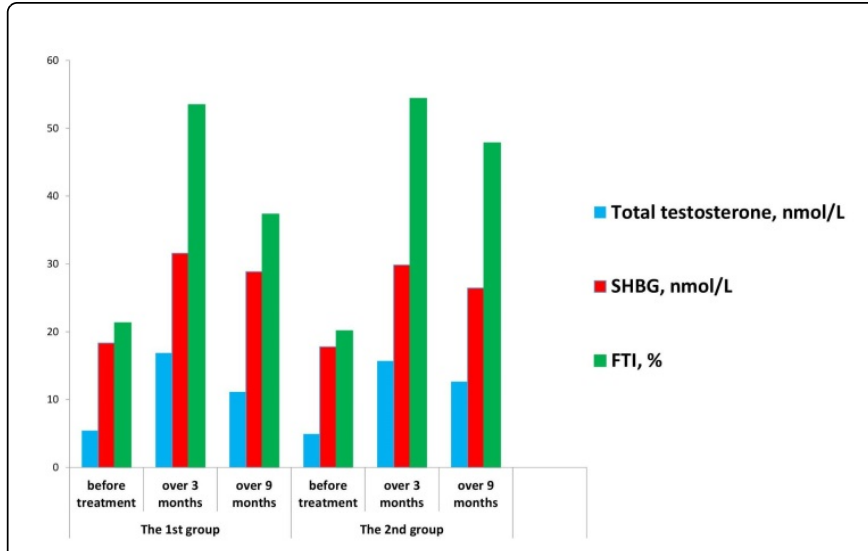

Figure 4: Hormonal ranges among the men of both groups in a process of treatment.

The ranges of total testosterone were already significant over 3 months after treatment among the patients of both groups (Figure 4).

With age, typical changes in water-salt metabolism take place; therefore, diagnostics of parameters in this type of exchange is rather informative too. Defining $\mathrm{K}^{+}, \mathrm{Na}^{+}$and $\mathrm{Cl}^{-}$, the same as $\mathrm{Ca}^{2+}$ and phosphorus is rather significant for dietary choice and assessment for concealed swellings. Intake of $\mathrm{Mg}^{2+}$ within the organism is important for normal cardiovascular system functions. Calcium and phosphorus are essential for growth and health of bone tissue, teeth and functions of nervous, muscular systems, as well as blood coagulation potential. These microelements are also indicators of hormonal imbalance and intestinal dysfunctions. Assessment of separate electrolytes was made among the patients of both groups (Table 1).

\begin{tabular}{|c|c|c|c|c|c|c|c|}
\hline & \multirow{3}{*}{ WNL } & \multicolumn{3}{|l|}{ The $1^{\text {st }}$ group } & \multicolumn{3}{|l|}{ The $2^{\text {nd }}$ group } \\
\hline & & \multirow[t]{2}{*}{ Before treatment } & \multicolumn{2}{|c|}{ After treatment } & \multirow[t]{2}{*}{ Before treatment } & \multicolumn{2}{|c|}{ After treatment } \\
\hline & & & $\begin{array}{l}\text { Over } \\
3 \text { months }\end{array}$ & $\begin{array}{l}\text { Over } \\
9 \text { months }\end{array}$ & & $\begin{array}{l}\text { Over } \\
3 \text { months }\end{array}$ & $\begin{array}{l}\text { Over } \\
9 \text { months }\end{array}$ \\
\hline $\begin{array}{l}\text { Potassium, } \\
\mathrm{mmol} / \mathrm{L}\end{array}$ & $3.5-5.1$ & $3.29 \pm 0.013$ & $3.52 \pm 0.023$ & $4.1 \pm 0.012$ & $3.32 \pm 0.014$ & $3.47 \pm 0.02$ & $4.3 \pm 0.015$ \\
\hline $\begin{array}{l}\text { Calcium } \\
\mathrm{mmol} / \mathrm{L}\end{array}$ & $1.16-1.32$ & $1.02 \pm 0.01$ & $1.19 \pm 0.03$ & $1.25 \pm 0.013^{*}$ & $1.04 \pm 0.021$ & $1.21 \pm 0.03$ & $1.31 \pm 0.02^{*}$ \\
\hline $\begin{array}{l}\text { Magnesium, } \\
\mathrm{mmol} / \mathrm{L}\end{array}$ & $0.66-1.07$ & $0.61 \pm 0.031$ & $0.71 \pm 0.041$ & $0.90 \pm 0.021^{*}$ & $0.60 \pm 0.0211$ & $0.87 \pm 0.05$ & $1.01 \pm 0.012^{*}$ \\
\hline Sodium, mmol/L & $136-145$ & $138 \pm 0.02$ & $142 \pm 0.012$ & $145 \pm 0.015$ & $140 \pm 0.011$ & $141 \pm 0.013$ & $143 \pm 0.016$ \\
\hline $\begin{array}{l}\text { Phosphorus, } \\
\mathrm{mmol} / \mathrm{L}\end{array}$ & $0.81-1.45$ & $0.75 \pm 0.02$ & $0.83 \pm 0.021$ & $1.21 \pm 0.013^{*}$ & $0.77 \pm 0.03$ & $1.01 \pm 0.021$ & $1.23 \pm 0.013^{*}$ \\
\hline
\end{tabular}

Table 1: Electrolyte ranges among the patients of both groups before and after treatment.

According to the data of our results, we recorded significant reduction of the ranges of calcium, magnesium and phosphorus shown both in patients of the $1^{\text {st }}$ and $2^{\text {nd }}$ groups before treatment. Over 9 months following FSCs treatment, significant elevation of such electrolytes was demonstrable among the patients of both groups. 
Hormonal functions of the organism could be estimated by defining thyroid gland hormones and may also envisage assessment of the levels of thyroid stimulating hormone (TSH), triiodothyronine (T3)-both free and total; as well as thyroxine (T4)-free and total thyroxine; including saturation index for thyroid hormones.

Thus, prior to FSCs treatment, the patients in both groups revealed a reduced level TSH and free T4 $(4.54 \mathrm{mkIU} / \mathrm{mL}$ TSH, 0.907 free T4, $\mathrm{ng} / \mathrm{dL}$ before treatment in the patients of the $1^{\text {st }}$ group; $4.49 \mathrm{mkIU} / \mathrm{mL}$ TSH vs. 0.89 for free T4, ng/dL among the patients of the $2^{\text {nd }}$ group, prior to treatment). The levels of TSH were significantly decreased already over 9 months following FSCs therapy and constituted 0.75 $\mathrm{mkIU} / \mathrm{mL}$ in the patients of the $1^{\text {st }}$ group; whereas the $2^{\text {nd }}$ group patients revealed the level of $0.89 \mathrm{mkIU} / \mathrm{mL}, \mathrm{p}<0.05$. The ranges of free T4 were significantly lower among the patients of the $2^{\text {nd }}$ group over 9 months after FSCs therapy (Figure 5).

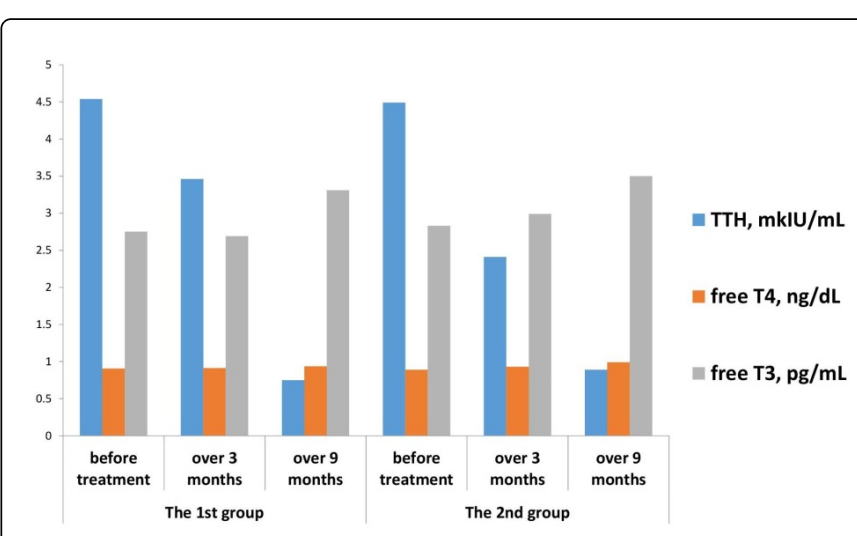

Figure 5: Dynamics of Thyroid hormones in the patients of both groups depending on FSCs treatment.

To the contrary, the task of antiaging and regenerative medicine consists in not only realizing future health problems, but also showing the way with opportunity for the patient to escape diseases or associated complications. In this respect, too much expectation would reply on the patient himself. Searching for a challenge to meet active senility, one must be ready to withdraw from harmful habits, to change mode of living and one's own insight. Likely choice as well as associated changes in activities of daily living would be much easier if patient feels support of close people and strikes a chord with a society. Therefore, prevention of age-related diseases is possible in a full extent only when community, as the whole, has been learned to be aware of urgent need of preserving active life in one's ripe old age.

Stem cells are currently used in different anti-aging treatments and are usually collected from a variety of tissues. FSCs are regarded as more stable compared to the other cells, a finding that can potentially open the door to new therapy options for prevention and management of aging-related diseases.

Among the patients who underwent treatment using FSCs preparations we revealed not only improvement of skin condition, specifically among the individuals in the $2^{\text {nd }}$ group, but also advantages for their internal strength of organism.
Ongoing studies for different effects promoted by FSCs to processes of human organism attrition envisage enormous contemporary opportunity for raising capacity of individuals to adapt to new social circumstances and environmental factors in order to prevent growing in numerous age-related diseases and to induce a suitable impact on overall lifespan and longer rates of productive life among people.

\section{Conflict of Interest}

The authors of the above study reported no conflict of interest at the moment of this article submission for publication within the journal.

\section{References}

1. Gavrylov LA, Gavrylova NS (1986) Biology of life expectancy. M Nauka 168.

2. Harman D (1956) Aging: a theory based on free radical and radiation chemistry. J Gerontol 11:298-300.

3. Skulachev VP (2007) A biochemical approach to the problem of aging: "megaproject" on membrane-penetrating ions. The first results and prospects. Biochemistry (Mosc) 72: 1385-1396.

4. Harman D (1972) The biologic clock: the mitochondria? J Am Geriatr Soc 20: 145-147.

5. De Grey AD (1997) A proposed refinement of the mitochondrial free radical theory of aging. Bioessays 19: 161-166.

6. Franceschi C, Bonafe M, Valensin S (2000) Human immunosenescence: the prevailing of innate immunity, the failing of clonotypic immunity, and the filling of immunological space. Vaccine 18: 1717-1720.

7. Dilman VM (1971) Age-associated elevation of hypothalamic, threshold to feedback control, and its role in development, aging, and disease. J Lancet 1: 1211-1219.

8. Dilman VM, Anisimov VN (1979) Hypothalmic mechanisms of ageing and of specific age pathology-I. Sensitivity threshold of hypothalamopituitary complex to homeostatic stimuli in the reproductive system. J Exp Gerontol 14: 161-174.

9. Fisher GJ (2005) The pathophysiology of photoaging of the skin. Cutis 75: 58-69.

10. Schmuth M, Watson RE, Deplewski D, Dubrac S, Zouboulis CC (2007) Nuclear hormone receptors in human skin. Horm Metab Res 39: 96-105.

11. Reichrath J, Lehmann B, Carlberg C, Varani J, Zouboulis CC (2007) Vitamins as hormones. Horm Metab Res 39: 71-84.

12. Verdier-Sévrain S, Bonte F, Gilchrest B (2006) Biology of estrogens in skin: implications for skin aging. Exp Dermatol 15: 83-94.

13. Hall G, Phillips TJ (2005) Estrogen and skin: the effects of estrogen, menopause, and hormone replacement therapy on the skin. J Am Acad Dermatol 53: 555-558.

14. Shin MH, Rhie GE, Park CH, Kim KH, Cho KH, et al. (2005) Modulation of collagen metabolism by the topical application of dehydroepiandrosterone to human skin. J Invest Dermatol 124:315-23.

15. Makrantonaki E, Zouboulis CC (2007) William J. Cunliffe Scientific Awards. Characteristics and pathomechanisms of endogenously aged skin. Dermatology 214: 352-360.

16. Makrantonaki E, Zouboulis CC (2007) Molecular mechanisms of skin aging: state of the art. Ann N Y Acad Sci 1119: 40-50.

17. Demchuk MP, Ivankova OV, Klunnyk MO (2017) Use of fetal stem cells for anti-aging and rejuvenation therapy. J Regenerative Med 6: 1.

18. Smikodub OI (2005) Method of treatment of people with embryonic cell suspensions. Patent, Ukraine. 